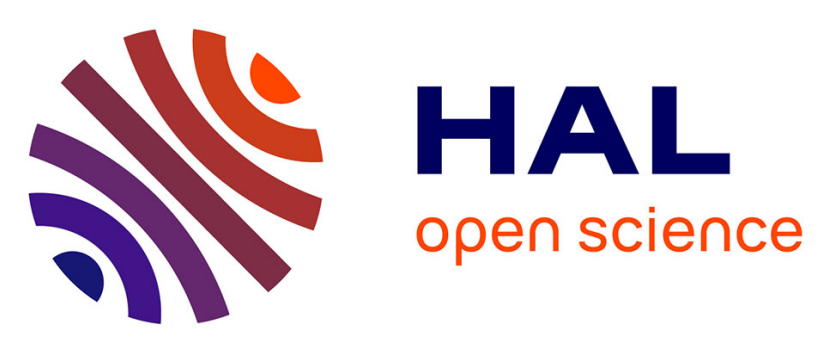

\title{
Comparison between DMRT simulations for multilayer snowpack and data from NoSREx report
}

\author{
Xuan-Vu Phan, Laurent Ferro-Famil, Michel Gay, Yves Durand, Marie
}

Dumont

\section{- To cite this version:}

Xuan-Vu Phan, Laurent Ferro-Famil, Michel Gay, Yves Durand, Marie Dumont. Comparison between DMRT simulations for multilayer snowpack and data from NoSREx report. IGARSS 2014 - IEEE International Geoscience and Remote Sensing Symposium, Jul 2014, Quebec, Canada. pp.5040 - 5043, 10.1109/IGARSS.2014.6947629 . hal-01118453

\section{HAL Id: hal-01118453 https://hal.science/hal-01118453}

Submitted on 19 Feb 2015

HAL is a multi-disciplinary open access archive for the deposit and dissemination of scientific research documents, whether they are published or not. The documents may come from teaching and research institutions in France or abroad, or from public or private research centers.
L'archive ouverte pluridisciplinaire HAL, est destinée au dépôt et à la diffusion de documents scientifiques de niveau recherche, publiés ou non, émanant des établissements d'enseignement et de recherche français ou étrangers, des laboratoires publics ou privés. 


\title{
COMPARISON BETWEEN DMRT SIMULATIONS FOR MULTILAYER SNOWPACK AND DATA FROM NOSREX REPORT.
}

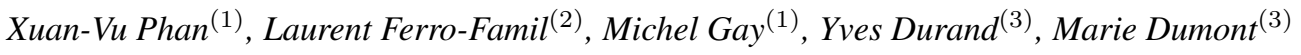 \\ ${ }^{(1)}$ Grenoble Image sPeech Signal and Automatics Lab \\ Grenoble INP, 11 rue des Mathématiques, BP 46, F-38402 StMartin d'Hères, France \\ ${ }^{(2)}$ Institut d'Electronique et des Télécommunications de Rennes \\ Université de Rennes 1, Bat. 11D, 263 avenue du Généreal Leclerc, F-35042 Rennes, France \\ ${ }^{(3)}$ CEN, MeteoFrance, 1441 rue de la Piscine, F-38400 Saint Martin d'Hères, France
}

\section{INTRODUCTION}

This paper presents a multilayer snowpack Electromagnetic Backscattering Model (EBM), based on Dense Media Radiative Transfer (DMRT). This model is capable of simulating the interaction of electromagnetic waves (EMW) at X-band and Ku-band frequencies with multilayer snowpack. The airsnow interface and snow-ground backscattering components are calculated using the Integral Equation Model (IEM), Fung et al. [1], whereas the volume backscattering component is calculated by the solution of Vector Radiative Transfer (VRT) equation at order 1 . We have applied these models using measurement data from NoSREx report [2], which includes SnowScat data in X-band and Ku-band, TerraSAR-X acquisitions and snowpack stratigraphic profiles. The results of model simulations show consistency with the radar observations, and therefore allow the EBM to be used in various applications, such as data assimilation [3],

\section{DENSE MEDIA RADIATIVE TRANSFER FOR MULTILAYER SNOWPACK}

The DMRT model simulates the multilayer snowpack backscattering coefficient in three components:

$$
\sigma_{0}=\sigma_{a s}+\sigma_{v}+\sigma_{g}
$$

This work has been funded by GlaRiskAlp, the European project (20102013) on glacial hazards in the Western Alps, MeteoFrance, the French national meteorological service and Energy de France (EDF). where:

- $\sigma_{a s}$ and $\sigma_{s g}$ represent respectively the air-snow and the snow-ground interfaces backscattering, calculated using the Integral Equation Model (IEM) Fung et al. [1].

- $\sigma_{v}$ represents the snowpack volume backscattering, calculated by resolving the VRT equation, Tsang et al. [4].

The physical parameters of a multilayer snowpack such as thickness, snow density and optical diameter of each layer are considered in the calculation of each layer's effective permittivity $\varepsilon_{e f f}$, which is based on the Strong Fluctuation Theory (SFT). Detailed equations can be found in Huining et al. [5]. Next, the extinction coefficient $\kappa_{e}$ can be derived: $\kappa_{e}=2 k_{0} \operatorname{Im}\left(\sqrt{\varepsilon_{e f f}}\right)$. This factor is then used in the calculation of various scattering mechanisms occurring during the propagation of EMW through a multilayer snowpack, which is categorized into 4 types: (1) transmission between two layers, (2) attenuation by the snow particles, (3) scattering and (4) coherent recombination.

Considering a snowpack made of $n$ distinct layers, where $\theta_{k}$ is the incidence angle and $d^{k}$ is the thickness of layer $k$, the total contribution of the volume backscattering mechanism $\sigma_{v}$ can be written as follows:

$$
\begin{aligned}
\sigma_{v}= & 4 \pi \cos \theta_{0} \sum_{k=1}^{n} \mathbf{A t t}_{u p}(k-1) \mathbf{T}_{(k-1) k} \\
& \frac{1-\exp \left(-\frac{2 \kappa_{e}^{k} d^{k}}{\cos \theta_{k}}\right)}{2 \kappa_{e}^{k}} \mathbf{P}^{k} \mathbf{T}_{k(k-1)} \mathbf{A t t}_{d o w n}(k-1)
\end{aligned}
$$


where Att represents the attenuation matrix, $\mathbf{T}$ represents the Fresnel trasmission matrix and $\mathbf{P}$ represents the phase matrix. The expressions of these factors can be found in Phan et al. [3].

\section{VALIDATION OF MODEL USING DATA FROM NOSREX REPORT}

In this study, data from NoSREx report [2] are used to evaluate the EBM (Electromagnetic Backscatter Model). In the following comparisons, it is worth mentioning that the snowpack stratigraphic profiles are not taken directly at the SnowScat radar footprint and the spatial variability of the snow stratigraphy is high. Consequently, the observations can only be used as a global reference of the evolution of snowpack and not as a precise reference of the snowpack conditions, which are measured by the radar.

In a first part, for comparing EBM model, we consider a single layer snowpack. The snow density is equal to $200 \mathrm{kgm}^{-3}$, mean density for the whole period in study and the effective snow grain radius is equal to $0.5 \mathrm{~mm}$. We use the snow water equivalent measured by the gamma wave instrument (GWI) [2]. The ground roughness is fixed $\sigma_{s g}=1 \mathrm{~cm}$ and $l_{s g}=8 \mathrm{~cm}$.

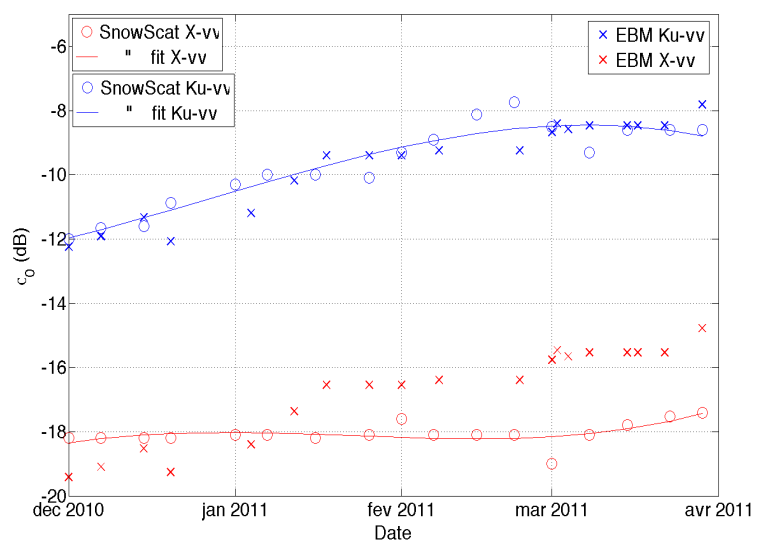

Fig. 1. Time series of measured by SnowScat [2] and simulated backscatter using EBM at Ku-(blue) and X-band(red), VV polarized, $40^{\circ}$ incidence angle.

Figure 1 shows the time series of simulated backscatter at $\mathrm{Ku}$ - and $\mathrm{X}$-band using the EBM in comparison with the SnowScat measurements from Sodankyla in winter 2010/2011. For both cases, Ku- and X-band, the EBM calculations are consistent with SnowScat measurements. However, it is important to note that the model is very sensitive to the grain radius, therefore if we take another value, the results will be changed.

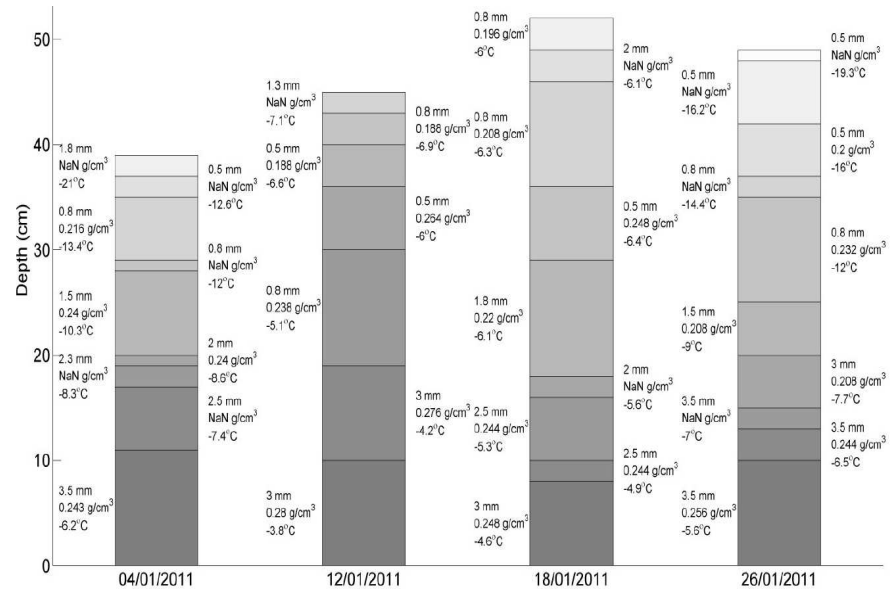

Fig. 2. Example of snowpack stratigraphic profiles measurements [2].

In a second part, we take account the snowpack stratigraphic profiles (Figure 2). The snow grain size is measured using visual analysis, which can be subject to human errors. In order to obtain the optical diameter to be used in the EBM, we have divided the measured snow grain size by a factor equal to 2.2 (experimental value, in future studies, we will prefer to use the optical diameter). The ground roughness is fixed $\sigma_{s g}=0.7 \mathrm{~cm}$ and $l_{s g}=8 \mathrm{~cm}$.

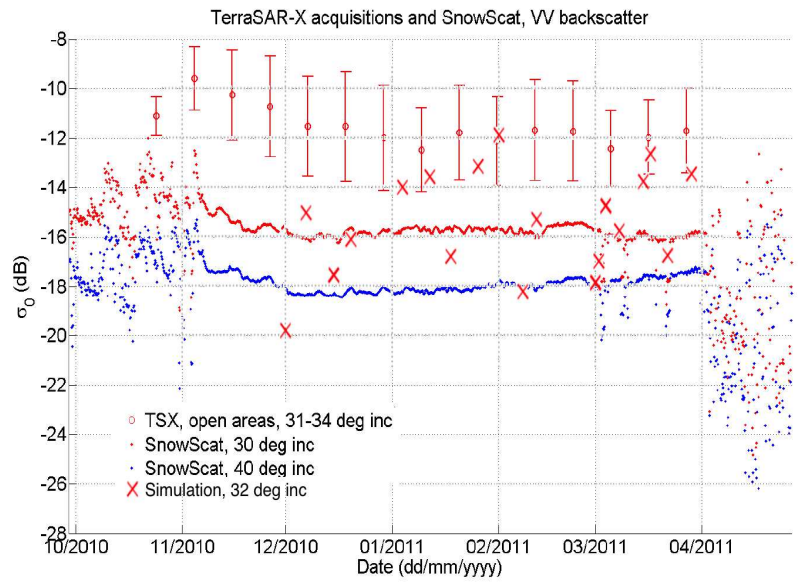

Fig. 3. Comparison of $\sigma_{0}$ observed by SnowScat at X-band frequency, TerraSAR-X and simulation of the EBM using insitu snowpack stratigraphic measurements [2]. 
Figure 3 represents the comparison of the backscattering coefficients $\sigma_{0}$ observed by SnowScat at X-band frequency, TerraSAR-X and simulation of the EBM using in-situ snowpack stratigraphic measurements [2]. One can see that the simulated backscattering coefficients (red cross) varies around the backscattering coefficients measured by SnowScat. The high variations in the value of simulated backscattering coefficients are due to the high sensitivity of the EBM model in the grain size. The tendencies of EBM simulations and SnowScat measurements seem consistent in the period of early March. However, we cannot reach a conclusion with respect to SnowScat and TerraSAR-X data, due to the large spatial variation of snowpack conditions.
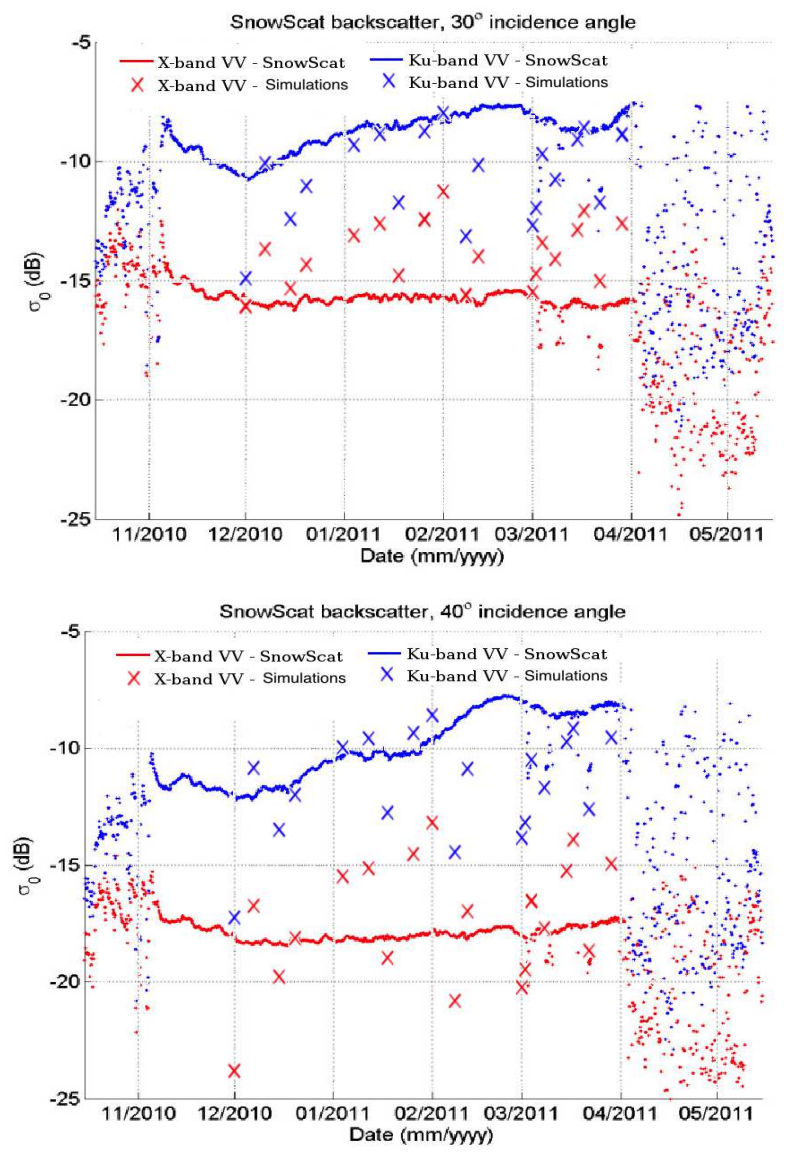

Fig. 4. Comparison of $\sigma_{0}$ measured by SnowScat at X-band and $\mathrm{Ku}$-band frequencies and simulation of the EBM using in-situ snowpack stratigraphic measurements [2], at incidence angles of $30^{\circ}$ (top) and $40^{\circ}$ (bottom).

Figure 4 shows the comparison of the backscattering coefficients $\sigma_{0}$ observed by SnowScat at X-band and Ku-band fre- quencies and simulation of the EBM using in-situ snowpack stratigraphic measurements. By observing the X-band simulations and observations (red cross and red line), we can see that the values of simulated backscattering coefficients at incidence angle of $30^{\circ}$ are higher than measurements, whereas at $40^{\circ}$ the values of simulations are more scattered around the values of measurements. This may due to the simulation value of snow-ground interface backscattering $\sigma_{g}$ is higher when the incidence angle is low. In Ku-band, the simulations and the measurements seem to show a similar tendency, especially on the period of January 2011 and early March 2011, where the tendencies are almost identical.

At this point, we assume that measurements of snow stratigraphy are wrong due to human error. We attempt to improve these measures using a data assimilation process Phan et al. [3] (not described in this paper).

Figure 5 shows the modifications of grain sizes produced by the assimilation process. The initial profiles come from in-situ snowpack stratigraphic measurements [2] (before vertical white line) and the final profiles result from assimilation (after vertical white line). One can see an overall decrease in grain size, which seems consistent with the finding that visual analysis tends to overestimate this value.

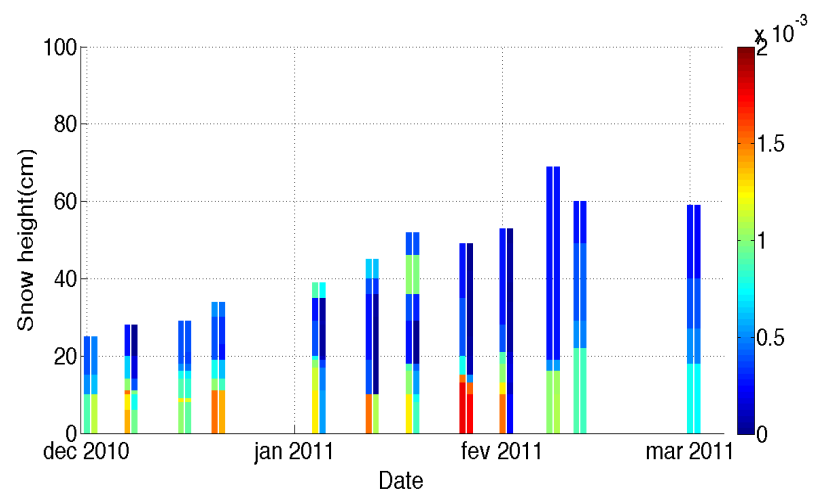

Fig. 5. Modification of grain sizes profiles (color blue $->$ red, corresponding to $0 \mathrm{~mm}->2 \mathrm{~mm}$ ) produced by the assimilation process to converge to SnowScat measurement at X-band (incidence angle of $30^{\circ}$ ).

Figure 6 shows changes in density produced by the assimilation process. The initial profiles come from in-situ measurements [2] (before vertical white line), thus the final profiles result from assimilation (after vertical white line). On observation, there is very little change in the density. We have 
done the assumption that the density measurement errors are low, therefore we have taken a low value in the error covariance matrix.

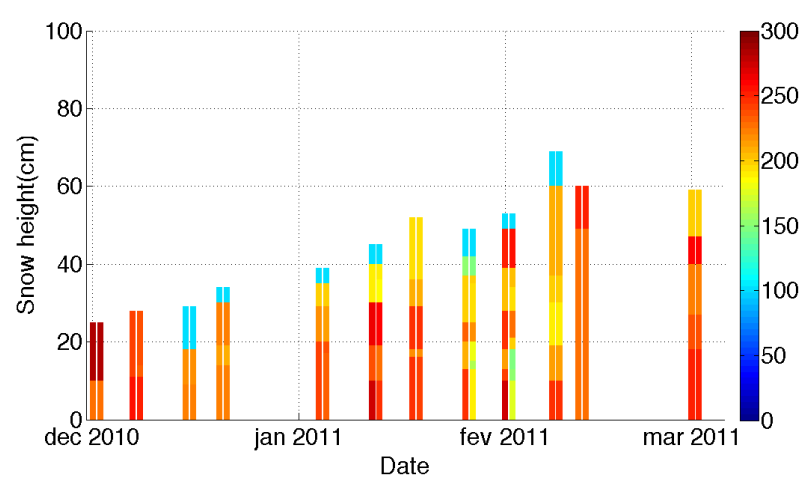

Fig. 6. Modification of density profiles produced by the assimilation process to converge to SnowScat measurement at $\mathrm{X}$-band (incidence angle of $30^{\circ}$ ).

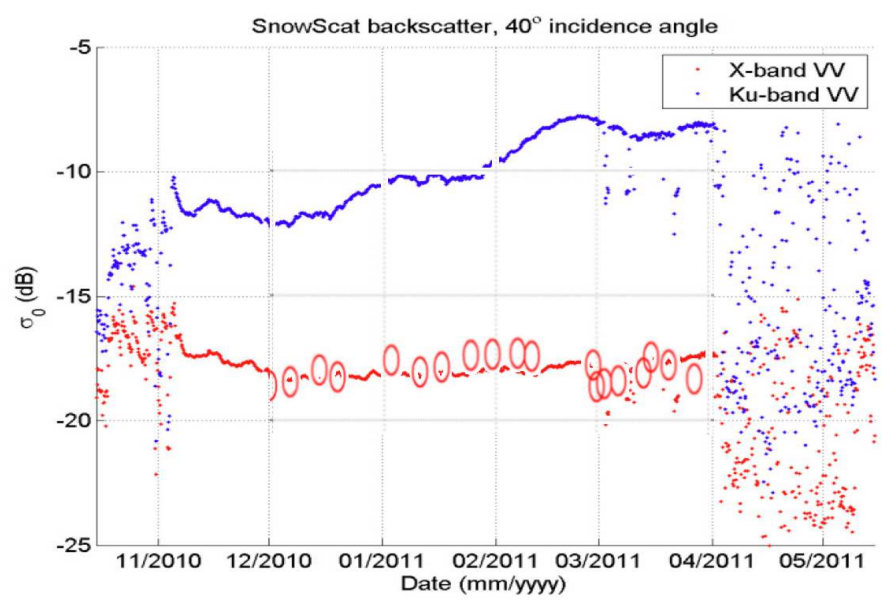

Fig. 7. Comparison of $\sigma_{0}$ measured by SnowScat at X-band frequencies (red line) and simulation with EBM at incidence angle of $40^{\circ}$ (red circle) using snowpack assimilated profiles at incidence angle of $30^{\circ}$.

Finally, we used the snowpack modified profiles by assimilation at $30^{\circ}$ to compare the $\sigma_{0}$ measured by SnowScat at X-band and simulated by EBM at incidence angle of $40^{\circ}$. Figure 7 shows that the EBM simulations with assimilation process (red circle) are very consistent with SnowScat measurements (red line).

\section{CONCLUSION}

In conclusion, the EBM simulations of backscattering coefficients and measurements from ground-based radar SnowScat as well as TerraSAR-X satellite show the same tendencies at certain sequences of measurement. The validation of this EBM model establishes a relationship between SAR observations and snow stratigraphic measurements (or physical model of snowpack evolution), which allows the development of different approaches, such as data assimilation of SAR data into a detailed snowpack model Phan et al. [3]. Changes are then made to the initial profiles through a process of assimilation to take into account human error measurement. These promising results also suggest the necessity of an experimental platform that allows automatic and continuous measurements of ground-based radar, coupled with regular observation of the snowpack evolution and SAR satellite acquisitions, in order to validate the electromagnetic model as well as physical models of snowpack and the assimilation process.

\section{REFERENCES}

[1] A.K. Fung and K.S. Chen, "An update on the iem surface backscattering model," Geoscience and Remote Sensing Letters, IEEE, vol. 1, no. 2, pp. 75 - 77, april 2004.

[2] J. Lemmetyinen, A. Kontu, J. Pulliainen, A. Wiesmann, C. Werner, T. Nagler, H. Rott, and M. Heidinger, "Technical assistance for the deployment of an $\mathrm{x}$ - to ku-band scatterometer during the nosrex ii experiment," Final Report, ESA ESTEC Contract No. 22671/09/NL/JA., 2011.

[3] X. V. Phan, L. Ferro-Famil, M. Gay, Y. Durand, M. Dumont, S. Morin, S. Allain, G. D’Urso, and A. Girard, “3dvar multilayer assimilation of x-band sar data into a detailed snowpack model," The Cryosphere Discussions, vol. 7, no. 5, pp. 4881-4912, 2013.

[4] L. Tsang, J. A. Kong, and R. T. Shin, Theory of microwave remote sensing, Wiley-Interscience, New York, 1985.

[5] W. Huining, J. Pulliainen, and M. Hallikainen, "Effective permittivity of dry snow in the 18 to 90 ghz range," Progress In Electromagnetics Research, vol. 24, pp. 119 $-138,1999$. 